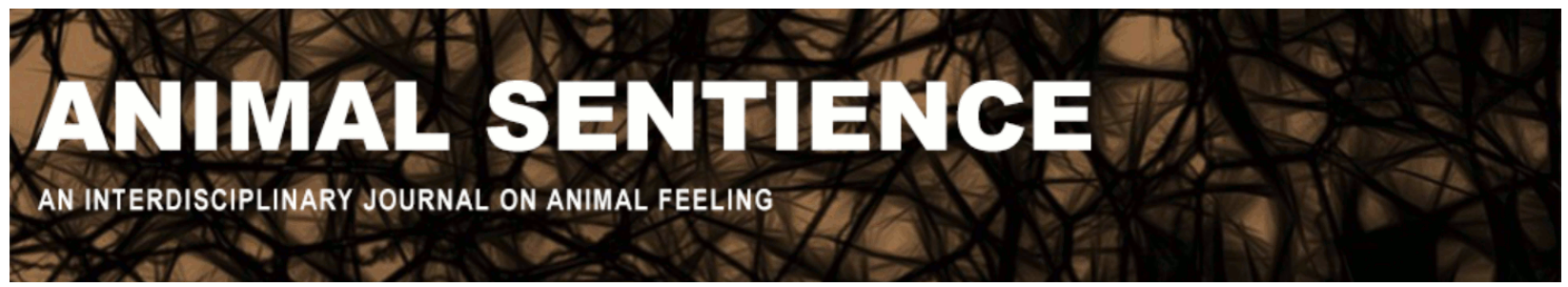

Gibbons, Matilda and Sarlak, Sajedeh (2020) Inhibition of pain or response to injury in invertebrates and vertebrates. Animal Sentience 29(34)

DOI: $10.51291 / 2377-7478.1649$

Date of submission: $2020-10-02$

Date of acceptance: 2020-10-03

(c)

This article has appeared in the journal Animal

Sentience, a peer-reviewed journal on animal

cognition and feeling. It has been made open access,

free for all, by WellBeing International and deposited

in the WBI Studies Repository. For more information,

please contact

wbisr-info@wellbeingintl.org.

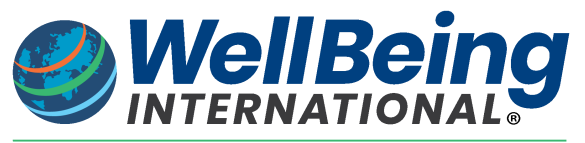

SOLUTIONS FOR PEOPLE, ANIMALS AND ENVIRONMENT 


\title{
Inhibition of pain or response to injury in invertebrates and vertebrates
}

\author{
Commentary on Mikhalevich \& Powell on Invertebrate Minds
}

\author{
Matilda Gibbons \\ School of Biological and Chemical Sciences, Queen Mary University of London \\ Sajedeh Sarlak \\ College of Agriculture \& Natural Resources, University of Tehran
}

\begin{abstract}
In certain situations, insects appear to lack a response to noxious stimuli that would cause pain in humans. For example, from the fact that male mantids continue to mate while being eaten by their partner it does not follow that insects do not feel pain; it could be the result of modulation of nociceptive inputs or behavioural outputs. When we try to infer the underlying mental state of an insect from its behaviour, it is important to consider the behavioural effects of the associated physiological and neurobiological mechanisms.
\end{abstract}

Matilda Gibbons is a PhD candidate at Queen Mary University of London, examining the neurobiology and behavioural responses of bees to determine whether invertebrates have pain experiences. Website

Sajedeh Sarlak is a PhD candidate in Entomology at the University of Tehran, Plant Protection Department, researching the responses of social bees to noxious stimuli and stress. Website

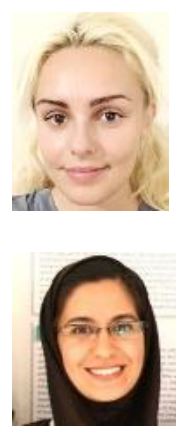

Mikhalevich \& Powell (2020) (M\&P)'s message is that we should aim to be consistent in our standards of judgement for ethical protection for all animals: some of the arguments against arthropod sentience could be used against sentience in any animal, even young humans. Evidence of behaviour caused by pain may be an indicator of sentience. In section 2.3.3, M\&P discuss instances where it appears there is evidence for a lack of pain behaviour in insects (Eisemann et al. 1984). These examples derive from three types of evidence:

1. Continuing to feed or mate whilst experiencing noxious damage

2. Not responding to noxious injury caused by a parasite

3. Not protecting the injury site (e.g., by putting weight onto the site of injury)

M\&P describe three potential conclusions that could be drawn from such evidence: (a) that these insects do not experience pain (Broom, 2013); (b) that they do not experience pain in the way that vertebrates do; or (c) that the circumstances generating pain in these lineages differ from those in vertebrates. We accept (b) and (c) as possible conclusions. We, will argue, however, that $(a)$ is not a logical conclusion for these types of evidence.

1. Continuing to feed or mate whilst experiencing noxious damage. It has been shown that in vertebrates such as chickens, cats and rats, hunger suppresses reactions to noxious stimuli (Casey and Morrow, 1983; Foo and Mason, 2005; Wylie and Gentle, 1998), possibly via the opioid system. This suppression has also been found in invertebrates, specifically gastropods (Davis et al., 1974; Gillette et al., 2000). Therefore, there appears to be a phylogenetically conserved system in which feeding suppresses the reaction to pain (Foo and Mason, 2009); this behavioural pattern may hence not be indicative of the true internal state of the insect. 
It has also been suggested that an insect may consume more food if it has an immune response to an injury in order to provide the energy to sustain the immune response (Junca and Sandoz, 2015; Groening et al., 2017). Schwartz et al. (2016) suggest that male mantids will self-sacrifice to sexual cannibalism during mating, even though this causes noxious injury, because it increases the number, size and survival of the offspring. This is perhaps comparable to how humans and other mammals endure the pain of childbirth. The benefits of sexual reproduction for the mantids seem to outweigh the pain that may be associated with it. Enduring sexual cannibalism is not good evidence of insentience in insects, because the actions of both feeding and mating can suppress the expression of responses to pain or injury in many species, vertebrate and invertebrate.

2. Not responding to noxious injury caused by a parasite. Some parasites are able to manipulate the host insect's behaviour, again making the behavior unrepresentative of the internal experience of the host. For example, the parasitic jewel wasp stings the cockroach and delivers neurotoxins into the cerebral ganglia to induce a "zombie-like" behaviour, in which the cockroach is unable to initiate movement and thus unable to engage in any stereotypical reaction to injury or pain (Gal \& Libersat 2010, Libersat et al. 2018). Prior to the delivery of neurotoxins, the cockroach responds by kicking, stabbing and biting at the wasp (Catania, 2018), thus demonstrating its awareness of the attack. The venom may elicit these changes by affecting not the motor system but the opioid system. The cockroach's startle response threshold to an electric shock after being stung is reduced if opioid antagonists are given, suggesting that the venom may have not just a paralytic effect but an analgesic one (Gavra and Libersat, 2010). It has also been shown that a parasitic wasp that develops inside a caterpillar temporarily desensitizes the body wall around the exit hole from which it is emerging (Adamo et al., 2016). The caterpillar does not appear to feel pain from the emergence of the parasite, but this is due to a dampening of nociceptive processing, not the inability to feel pain. No conclusion about the existence of a painful mental state in insects can be drawn from this kind of evidence.

3. Not protecting the injury site. There are numerous examples of insects appearing to protect an injury site in different ways. For example, an increase in self-grooming after injury has been identified in cockroaches (Weisel-Eichler et al., 1999), drosophila (Corfas and Dudai, 1989), ants (Ugelvig et al., 2010) and bees (Cox and Wilson, 1984; Hurst et al., 2014). In addition, when the leg that a praying mantis uses to groom itself is removed, its contralateral leg takes over even though it produces a non-functional motion, suggesting that this behaviour is plastic and not a reflex (Zack, 1978; Zhukovskaya et al., 2013). Termite-hunting ants have been shown to carry back injured ants to the nest and treat their injuries with grooming, which seems to help prevent infection and reduce mortality (Frank et al., 2018). The injured ants also acted 'more injured' when they were around nest-mates, suggesting awareness of the contingency. Hence insects seem to engage in certain types of selfprotective behaviour in response to injury that goes beyond a reflexive response.

Avoidance of putting weight on a leg injury during locomotion has only been reported in anecdotal observations, but not experimentally tested, in insects (Eisemann et al. 1984). In mammals, this reaction occurs due to an injury eliciting an inflammatory reaction and causing hyperalgesia and allodynia, making the injury site more sensitive to nociceptive processing and thus more painful (Sandkühler, 2009). It has been shown that a similar process may be occurring when spiders autotomize an injured leg (Eisner and Camazine 1983): automatization can be initiated by injecting histamine, serotonin and phospholipase, all of 
which contribute to hyperalgesic and allodynic states in mammals (Coutaux et al., 2005), Combined with the evidence of non-reflexive protective behaviour this suggests that there may be differences in the specific protective behaviour between insects and humans, but that such behaviours may have the same function: to lessen further damage to the site of injury.

Conclusion. Whether insects can feel pain cannot be determined from the three kinds of evidence described above. The most circumspect conclusion from these kinds of evidence is either that if insects feel pain, (i) what they feel is different from what vertebrates feel; or (ii) the circumstances that induce pain in these lineages differ from those in vertebrates. There may, of course, be evidence elsewhere that strongly suggests that insects do not feel pain, but these particular examples do not constitute such evidence.

\section{References}

Adamo, S. A., Kovalko, I., Turnbull, K. F., Easy, R. H., \& Miles, C. I. (2016). The parasitic wasp Cotesia congregata uses multiple mechanisms to control host (Manduca sexta) behaviour. Journal of Experimental Biology, 219(23), 3750-3758.

Broom, D.M. The welfare of invertebrate animals such as insects, spiders, snails and worms. In Animal Suffering: From Science to Law; van der Kemp, T.A., Lachance, M., Eds.; Editions Yvon Blais: Paris, France, 2013; 135-152.

Casey, K.L. and Morrow, T.J. (1983). Nocifensive responses to cutaneous thermal stimuli in the cat: stimulus-response profiles, latencies, and afferent activity. Journal of Neurophysiology, 50(6), 1497-1515.

Catania, K.C. (2018). How Not to Be Turned into a Zombie. Brain, Behavior and Evolution, 92(1-2), 32-46.

Corfas, G. and Dudai, Y. (1989). Habituation and dishabituation of a cleaning reflex in normal and mutant Drosophila. The Journal of Neuroscience, 9(1), 56- 62.

Coutaux, A., Adam, F., Willer, J.-C. and Le Bars, D. (2005). Hyperalgesia and allodynia: peripheral mechanisms. Joint Bone Spine, 72(5), 359-371.

Cox, R. and Wilson, W. (1984). Effects of Permethrin on the Behavior of Individually Tagged Honey Bees,Apis melliferaL. (Hymenoptera: Apidae). Environmental Entomology, 13(2): 375-378.

Davis, W.J., Mpitsos, G.J. and Pinneo, J.M. (1974). The behavioral hierarchy of the mollusk Pleurobranchaea. Journal of Comparative Physiology, 90(3), 207-224.

Dheilly, N.M., Maure, F., Ravallec, M., Galinier, R., Doyon, J., Duval, D., Leger, L., Volkoff, A.N., Missé, D., Nidelet, S., Demolombe, V., Brodeur, J., Gourbal, B., Thomas, F. and Mitta, G. (2015). Who is the puppet master? Replication of a parasitic waspassociated virus correlates with host behaviour manipulation. Proceedings of the Royal Society B: Biological Sciences, [online] 282(1803), p.20142773.

Eisemann, C. H., et al. “Do Insects Feel Pain? - A Biological View." Experientia, vol. 40, no. 2, Feb. 1984, 164-167, 10.1007/bf01963580.

Eisner, T. and Camazine, S. (1983). Spider leg autotomy induced by prey venom injection: An adaptive response to "pain"? Proceedings of the National Academy of Sciences, 80(11), 3382-3385. 
Foo, H. and Mason, P. (2005). Sensory suppression during feeding. Proceedings of the National Academy of Sciences, 102(46), 16865-16869.

Foo, H. and Mason, P. (2009). Analgesia Accompanying Food Consumption Requires Ingestion of Hedonic Foods. Journal of Neuroscience, 29(41), 13053-13062.

Frank, E.T., Wehrhahn, M. and Linsenmair, K.E. (2018). Wound treatment and selective help in a termite-hunting ant. Proceedings of the Royal Society B: Biological Sciences, 285(1872), p.20172457.

Gal, R. and Libersat, F. (2010). A Wasp Manipulates Neuronal Activity in the Sub-Esophageal Ganglion to Decrease the Drive for Walking in Its Cockroach Prey. PLOS ONE, 5(4), p.e10019.

Gavra, T. and Libersat, F. (2010). Involvement of the opioid system in the hypokinetic state induced in cockroaches by a parasitoid wasp. Journal of Comparative Physiology $A$, 197(3), 279-291.

Gillette, R., Huang, R.-C., Hatcher, N. and Moroz, L.L. (2000). Cost-benefit analysis potential in feeding behavior of a predatory snail by integration of hunger, taste, and pain. Proceedings of the National Academy of Sciences, 97(7), 3585-3590.

Groening, J., Venini, D. and Srinivasan, M.V. (2017). In search of evidence for the experience of pain in honeybees: A self-administration study. Scientific Reports, 7(1).

Hurst, V., Stevenson, P. and Wright, G. (2014). Toxins induce 'malaise' behaviour in the honeybee (Apis mellifera). Journal of Comparative Physiology A, 200(10), 881-890.

Junca, P. and Sandoz, J.-C. (2015). Heat Perception and Aversive Learning in Honey Bees: Putative Involvement of the Thermal/Chemical Sensor AmHsTRPA. Frontiers in Physiology, 6.

Libersat, F., Kaiser, M., \& Emanuel, S. (2018). Mind control: how parasites manipulate cognitive functions in their insect hosts. Frontiers in psychology, 9, 572.

Mikhalevich, I. and Powell, R. (2020) Minds without spines: Evolutionarily inclusive animal ethics. Animal Sentience 29(1).

Sandkühler, J. (2009). Models and mechanisms of hyperalgesia and allodynia. Physiological Reviews, 89(2): 707-58.

Schwartz, S.K., Wagner, W.E. and Hebets, E.A. (2016). Males Can Benefit from Sexual Cannibalism Facilitated by Self-Sacrifice. Current Biology, 26(20), 2794-2799.

Ugelvig, L., Kronauer, D., Schrempf, A., Heinze, J. and Cremer, S. (2010). Rapid anti-pathogen response in ant societies relies on high genetic diversity. Proceedings of the Royal Society B: Biological Sciences, 277(1695), 2821-2828.

Weisel-Eichler, A., Haspel, G. and Libersat, F. (1999). Venom of a parasitoid wasp induces prolonged grooming in the cockroach. Journal of Experimental Biology 1999, 202, 957-964.

Wylie, L.M. and Gentle, M.J. (1998). Feeding-induced Tonic Pain Suppression in the Chicken: Reversal by Naloxone. Physiology \& Behavior, 64(1), 27-30.

Zack, S. (1978). The effects of foreleg amputation on head grooming behaviour in the praying mantis, Sphodromantis lineola. Journal of Comparative Physiology ? A, 125(3), 253-258.

Zhukovskaya, M., Yanagawa, A. and Forschler, B. (2013). Grooming Behavior as a

Mechanism of Insect Disease Defense. Insects, 4(4), 609-630. 